\title{
Velhas Teses, Novos Dados: Uma Análise Metodológica*
}

\author{
Wanderley Guilherme dos Santos
}

$D$ ados publicou em seu número 1, volume 47 (2004), artigo de Jairo Nicolau reportando resultados de pesquisa sobre o destino partidário dos votos em coligações no período 1945-62. Conheci uma primeira versão bastante preliminar do relatório em que se enfatizava, principalmente, o processo da pesquisa e seu sucesso, anunciando a possibilidade de que as descobertas pudessem trazer substanciais modificações em seções do conhecimento especializado.

A versão publicada em Dados é, para mim, inédita, salvo os dados utilizados para identificar os eleitos por coligação. Essa era uma lacuna nos estudos sobre o sistema partidário brasileiro, especificamente no período 1950-64, pois nas primeiras competições pós-ditadura varguista, em 1946, não foram permitidas coligações nas eleições proporcionais. À parte os votos dados nominalmente a candidatos individualizados e aqueles depositados na legenda pela qual se inclinava o eleitor, os demais votos abasteciam as coligações entre partidos. $\mathrm{O}$ Tribunal Superior Eleitoral - TSE não discriminava os votos nominais nem em legendas, quando via coligações, obrigando os estudiosos à utilização de estratagemas para superar a deficiência. Segundo Nico-

* Como de costume, o Autor agradece as intervenções críticas no texto operadas por Tema Pechman e Charles Pessanha.

DADOS - Revista de Ciências Sociais, Rio de Janeiro, Vol. 47, nำ4, 2004, pp. 729 a 762. 
lau, tais estratagemas têm limites, entre eles o de não deixar saber ao certo "como foi a evolução da votação dos partidos nos estados, nem [teria sido] possível calcular com precisão uma série de indicadores que dependem da especificação dos votos de cada partido para serem calculados" (:86).

O juízo não está bem formulado, visto que o problema que os novos dados pretendem elucidar é outro. Era e é possível avaliar a evolução do sistema partidário-parlamentar daquele período, tanto quanto calcular indicadores relevantes. Em termos metodologicamente rigorosos, o que se fazia era aceitar o postulado ${ }^{1}$ de que a falha nas informações não seria de magnitude suficiente para comprometer os resultados obtidos sem elas. Aceita a premissa, os resultados de todos os cálculos não deixavam de ser precisos, embora processados sobre base incompleta de informações. A identificação dos votos em coligações permite o que, a seguir, afirma Nicolau: "A dúvida é se a ausência desses dados não pode ter distorcido as análises, apontando tendências (ou deixando de apontá-las) que só poderiam ser assinaladas com precisão mediante os resultados eleitorais" (ibidem). Nicolau está seguro de que a resolução da incógnita dos votos em coligações trará alterações substantivas nas hipóteses preservadas pela literatura. As perguntas de que o presente artigo se ocupa são as seguintes: é procedente a afirmação de que o estoque de conhecimento disponível é retificado em grande extensão? Procede o juízo de que o estoque de conhecimento disponível sobre o sistema partidário daquele período é falsificado pelas novas evidências? Ou, contrariamente, as retificações são marginais e não há acréscimo de conhecimento substantivo em razão do acréscimo de informações?

Ao fim de meticuloso rastreamento de dados, Nicolau propõe uma reorganização da estatística eleitoral da República de 1946 destinada a dirimir dúvidas, depois de estabelecer, segundo ele, qual era a filiação partidária de $88 \%$ dos 5.242 candidatos que disputaram as eleições de 1945, 1950, 1954, 1958 e 1962. Para efeito de precisão, registre-se que grande parte dos candidatos não era, de fato, desconhecida, pois que um número considerável deles estava identificado, agregados na enorme massa de dados sobre as votações nominais e nas legendas (são sete volumes do TSE transcrevendo exatamente essas informações), restando por identificar os que se elegeram via coligações. De qualquer modo, o resultado é satisfatório, tendo o total de 
votos dos já identificados, acrescido aos agora recuperados, alcançado $96 \%$ dos votos depositados no período 1945-62.

Estabelecida a nova organização dos dados, Nicolau propõe-se a corrigir opiniões correntes sobre a evolução do grau de nacionalização dos partidos, teses sobre alterações na distribuição das cadeiras na Câmara dos Deputados entre partidos conservadores e progressistas, outras sobre a trajetória da dispersão eleitoral e parlamentar, e ainda outras sobre a volatilidade dos votos entre eleições. O programa revisionista é de grande porte, exigindo tratamento pormenorizado. A fidedignidade da nova estatística eleitoral parece indiscutível, e o esforço para estabelecê-la, louvável. Isto feito, a questão substantiva consiste em saber, como sustenta Nicolau, se a identificação dos candidatos e partidos eleitos através das coligações acrescenta informação surpreendente ao estoque de conhecimento acumulado pela literatura e se tal informação subverte as teses correntes. Para tanto, é indispensável ter uma idéia da extensão dos reparos feitos. A seguir encontram-se a tabela construída com os dados do TSE e a tabela reconstruída por Nicolau com base nas informações desse mesmo Tribunal, retificadas pelas identificações a que procedeu. Comparando as duas, e havendo sublinhado, na tabela do TSE, os números discrepantes, descobre-se que:

a) das 60 observações no período 1945-62, 21 foram retificadas (35,0\%), assim distribuídas: 2 em 1945, 2 em 1950, 7 em 1954, 3 em 1958 e 7 em 1962;

b) das 21 retificadas, em 13 (62,0\%) o valor da retificação foi inferior a 1,0 ponto percentual;

c) das 8 restantes, das $21,6(26,1 \%)$ sofreram retificações entre 1,1 e 1,5 pontos percentuais;

d) as outras 2, uma foi retificada em 2,7 (PTB em 1962) e outra em 1,8 pontos percentuais (PSD em 1962) ${ }^{2}$.

Em princípio, apenas 2 casos, em 60 observações (os da linha $d$ acima), justificariam a suspeita de sérias implicações substantivas. Continuando, entretanto, com a delimitação do problema, torna-se obrigatório esclarecer os comentários de Nicolau às tabelas retificadas. As listas do TSE, depois das eleições, enumeram os candidatos eleitos e os candidatos derrotados, os quais, automaticamente, são registrados 
Tabela 1

Tabela TSE

Distribuição de Cadeiras entre os Partidos

após Cinco Eleições Federais (1945-1962)

(em números absolutos e \%)

\begin{tabular}{|c|c|c|c|c|c|c|c|c|c|c|}
\hline \multirow[t]{2}{*}{ Partidos } & \multicolumn{2}{|c|}{1945} & \multicolumn{2}{|c|}{1950} & \multicolumn{2}{|c|}{1954} & \multicolumn{2}{|c|}{1958} & \multicolumn{2}{|c|}{1962} \\
\hline & $\mathbf{N}$ & $\%$ & $\mathbf{N}$ & $\%$ & $\mathbf{N}$ & $\%$ & $\mathbf{N}$ & $\%$ & $\mathbf{N}$ & $\%$ \\
\hline $\mathrm{PSD}^{* *}$ & 151 & 52,8 & 112 & 36,8 & 114 & 35,0 & 115 & 35,3 & 118 & 28,8 \\
\hline UDN & 77 & $\underline{26,9}$ & 81 & 26,6 & 74 & 22,7 & 70 & 21,5 & 91 & 22,2 \\
\hline РTB & 22 & 7,7 & 51 & 16,8 & 56 & $\underline{17,2}$ & 66 & $\underline{20,2}$ & 116 & $\underline{28,4}$ \\
\hline PSP & 2 & 0,7 & 24 & 7,9 & 32 & $\underline{9,8}$ & 25 & 7,7 & 21 & 5,1 \\
\hline PR & 7 & $\underline{2,4}$ & 11 & $\underline{3,6}$ & 19 & $\underline{5,8}$ & 17 & 5,2 & 4 & $\underline{1,0}$ \\
\hline PST & - & - & 9 & 3,0 & 2 & 0,6 & 2 & 0,6 & 7 & 1,7 \\
\hline PL & 1 & 0,3 & 5 & $\underline{1,6}$ & 8 & $\underline{2,4}$ & 3 & 0,9 & 5 & 1,2 \\
\hline PTN & - & - & 5 & 1,6 & 6 & 1,8 & 7 & $\underline{2,1}$ & 11 & 2,7 \\
\hline PRT & - & - & 1 & 0,3 & 1 & 0,3 & 2 & 0,6 & 3 & 0,7 \\
\hline PSB & - & - & 1 & 0,3 & 3 & $\underline{0,9}$ & 9 & 2,8 & 5 & $\underline{1,2}$ \\
\hline PDC & 2 & 0,7 & 2 & 0,7 & 2 & 0,6 & 7 & 2,1 & 20 & $\underline{4,9}$ \\
\hline PRP & - & - & 2 & 0,7 & 3 & $\underline{0,9}$ & 3 & 0,9 & 5 & $\underline{1,2}$ \\
\hline S/Part. & - & - & - & - & 6 & 1,8 & - & - & - & - \\
\hline MTR & - & - & - & - & - & - & - & - & 3 & 0,7 \\
\hline РCB & 14 & 4,9 & - & - & - & - & - & - & - & - \\
\hline PPS & 4 & 1,4 & - & - & - & - & - & - & - & - \\
\hline $\mathrm{UDN} / \mathrm{PR}^{*}$ & 6 & 2,1 & - & - & - & - & - & - & - & - \\
\hline Total & 286 & 100,0 & 304 & 100,0 & 326 & 100,0 & 326 & 100,0 & 409 & 100,0 \\
\hline
\end{tabular}

Fonte: TSE, diversos volumes.

* Observação: Na tabela retificada, 4 dos 6 eleitos pela coligação UDN/PR são acrescentados aos 77 da contagem inicial; os outros dois, imagino que expliquem a diferença de outra discrepância, 7 para o PR, na tabela do TSE, e 9 na tabela retificada. Um caso que parece controverso é o do PSP, em 1945, que conta com 2 cadeiras, na tabela no TSE, e com nenhuma na retificada. Em compensação, na tabela retificada surgem 2 cadeiras para um PRProg, que não existe na tabela do TSE. No conjunto de todas as observações, esse ponto indeciso não tem, contudo, qualquer peso.

** Ver Glossário ao final do artigo. 
Tabela 1A

Tabela Retificada

Número de Cadeiras (Absoluto e Percentual) por Ano e Partido

Câmara dos Deputados (1945-1962)

\begin{tabular}{|c|c|c|c|c|c|c|c|c|c|c|}
\hline \multirow[t]{2}{*}{ Partidos } & \multicolumn{2}{|c|}{1945} & \multicolumn{2}{|c|}{1950} & \multicolumn{2}{|c|}{1954} & \multicolumn{2}{|c|}{1958} & \multicolumn{2}{|c|}{1962} \\
\hline & $\mathbf{N}$ & $\%$ & $\mathbf{N}$ & $\%$ & $\mathbf{N}$ & $\%$ & $\mathbf{N}$ & $\%$ & $\mathbf{N}$ & $\%$ \\
\hline PSD & 151 & 52,8 & 112 & 36,8 & 119 & 36,5 & 119 & 36,5 & 125 & 30,6 \\
\hline UDN & 81 & 28,3 & 81 & 26,6 & 74 & 22,7 & 70 & 21,5 & 96 & 23,5 \\
\hline РTB & 22 & 7,7 & 51 & 16,8 & 61 & 18,7 & 63 & 19,3 & 105 & 25,7 \\
\hline PCB & 14 & 4,9 & & & & & & & & \\
\hline PR & 9 & 3,1 & 10 & 3,3 & 18 & 5,5 & 17 & 5,2 & 7 & 1,7 \\
\hline PPS & 4 & 1,4 & & & & & & & & \\
\hline PRProg. & 2 & 0,7 & & & & & & & & \\
\hline PSP & & & 24 & 7,9 & 27 & 8,3 & 25 & 7,7 & 21 & 5,1 \\
\hline PDC & 2 & 0,7 & 2 & 0,7 & 2 & 0,6 & 7 & 2,1 & 19 & 4,6 \\
\hline PL & 1 & 0,3 & 6 & 2,0 & 10 & 3,1 & 3 & 0,9 & 5 & 1,2 \\
\hline PST & & & 9 & 3,0 & & & 2 & 0,6 & 7 & 1,7 \\
\hline PTN & & & 5 & 1,6 & 6 & 1,8 & 6 & 1,8 & 11 & 2,7 \\
\hline PSB & & & 1 & 0,3 & 4 & 1,2 & 9 & 2,8 & 4 & 1,0 \\
\hline PRP & & & 2 & 0,7 & 4 & 1,2 & 3 & 0,9 & 3 & 0,7 \\
\hline PRT & & & 1 & 0,3 & 1 & 0,3 & 2 & 0,6 & 3 & 0,7 \\
\hline MTR & & & & & & & & & 3 & 0,7 \\
\hline Total & 286 & 100,0 & 304 & 100,0 & 326 & 100,0 & 326 & 100,0 & 409 & 100,0 \\
\hline
\end{tabular}

Fonte: Nicolau (2004:90, Tabela 3).

como suplentes. Por essa característica da lei, é possível calcular o número dos que se apresentaram como candidatos, antes das eleições: basta somar candidatos eleitos e candidatos suplentes e se chega ao total dos candidatos pré-momento eleitoral. Nas listas pós-eleitorais, tal como nas listas de antes das eleições, os candidatos por coligações não têm suas legendas de origem reconhecidas. Fique registrado, então, que o problema da identificação se refere somente aos eleitos, dos 
quais se ignora o partido de origem. São conhecidas e transcritas nas estatísticas do TSE as legendas partidárias de todos os demais candidatos. Felizmente, portanto, Nicolau não foi obrigado a investigar os 5.242 candidatos do período, tampouco os 1.365 efetivamente eleitos nas cinco Legislaturas consideradas. A Tabela 2 complementa a informação de Nicolau, discriminando, por eleição e partido, o número de eleitos não identificados pelas listas do TSE.

Tabela 2

Candidatos Não Identificados pelo TSE, Eleitos por Coligação, por Partido

Câmara dos Deputados (1950-1962)

\begin{tabular}{c|c|c|c|c|c}
\hline Partidos & $\mathbf{1 9 5 0}$ & $\mathbf{1 9 5 4}$ & $\mathbf{1 9 5 8}$ & $\mathbf{1 9 6 2}$ & Total \\
\hline PSD & 21 & 45 & 46 & 39 & 151 \\
UDN & 29 & 23 & 27 & 36 & 115 \\
PTB & 7 & 7 & 20 & 53 & 87 \\
PSP & 7 & 8 & 18 & 15 & 48 \\
PR & 6 & 12 & 3 & - & 21 \\
PST & - & 2 & - & 5 & 7 \\
PL & 3 & 5 & 1 & 3 & 12 \\
PTN & - & 1 & 7 & 11 & 19 \\
PRT & - & - & 2 & 3 & 5 \\
PSB & 1 & 1 & 9 & 5 & 16 \\
PDC & 2 & 1 & 1 & 19 & 23 \\
PRP & 1 & 1 & 1 & 4 & 7 \\
\hline Efeitos Coligação & $\mathbf{7 7}$ & $\mathbf{1 0 6}$ & $\mathbf{1 3 5}$ & $\mathbf{1 9 3}$ & $\mathbf{5 1 1}$ \\
Tamanho da Câmara & $\mathbf{3 0 4}$ & $\mathbf{3 2 6}$ & $\mathbf{3 2 6}$ & $\mathbf{4 0 9}$ & $\mathbf{1 . 3 6 5}$ \\
\hline $\mathbf{2 5 , 3}$ & $\mathbf{3 2 , 5}$ & $\mathbf{4 1 , 4}$ & $\mathbf{4 7 , 2}$ & $\mathbf{3 7 , 4}$ \\
\hline
\end{tabular}

Fonte: Ver nota 2.

Nicolau crê possível encontrar implicações de ordem substantiva com base na identificação de 511 casos, equivalentes a 37,4\% de todos os eleitos para a Câmara de Deputados, de 1950 a 1962. Exponho e co- 
mento, a seguir, os principais argumentos de Nicolau, questão a questão, salvo a última.

Tratando da expansão ou declínio dos partidos, que Gláucio Soares estimava estar ocorrendo em relação ao PTB, de um lado, e ao PSD e UDN, de outro, Nicolau confirma a opinião de Soares de que o PTB se expandiu entre o fim e o início do período (1945-62), mas considera relevante apresentar a qualificação de que parte da expansão, em 1950, "provavelmente, se deveu ao fato de o PCB não participar da disputa, e outra parte aos reflexos da candidatura vitoriosa de Getulio Vargas à Presidência" (:91). A qualificação, note-se, introduz juízo de probabilidades, e não mais de precisão. Sendo assim, caberia a sugestão da hipótese de que a expansão resultou de uma difusão organizacional do PTB, igualmente mencionada por Soares, nunca investigada sistematicamente, lembrando que o PSD e a UDN nasceram praticamente organizados, tendo seus quadros composto o governo e a oposição no período varguista anterior. Ainda no conjunto dos "prováveis", é possível que a urbanização também tenha contribuído para o crescimento petebista, como é reiterado na literatura. Juntas, as duas hipóteses aqui acrescentadas ajudariam, sem dúvida, a esclarecer o que teria levado o PTB a novo salto nas eleições de 1962, depois da crise da renúncia de Jânio e posse de Jango. O tema da renúncia de Jânio e posse de Jango, outra possibilidade, poderia ter sido convocado por $\mathrm{Ni}$ colau, como hipótese, assim como, anteriormente (para a eleição de 1950), convocara a eleição de Vargas. Preferiu, contudo, deixar sem explicação, pelo menos hipotética, como fizera antes, o importante salto numérico da bancada do PTB, em 1962, que, afinal, corrobora a tese de Soares sobre o crescimento do PTB ao longo do período. Fundamental para a presente discussão é que, não obstante as retificações da informação primária, continuamos dependentes de explicações "prováveis" sobre a evolução dos votos em partidos progressistas.

Quanto aos conservadores PSD e UDN, Nicolau contrasta a primeira eleição (1945) com a última (1962) e corrobora uma substancial queda na votação do PSD. Nesta comparação entre extremos, a tese de Soares sobre o relativo decréscimo histórico do PSD fica igualmente atestada. Lembre-se, entretanto, que a eleição de 1945, a primeira depois da remoção da ditadura, não foi de modo algum típica, com 52,8\% das cadeiras da Câmara de Deputados sendo controladas pelo PSD e 7,7\% pelo PTB. Razoável, portanto, que os resultados das eleições de 1950 fossem mais realistas, sendo a partir deles que a tese de Soares se mos- 
tra excessiva em relação aos dados. Para o ponto nevrálgico da dúvida de fundo, contudo, o aspecto crucial é que tanto os resultados de 1945, quanto os de 1950, para PSD e PTB, são os mesmos na tabela do TSE e na tabela retificada.

Em conclusão, a hipótese de que o PTB se expandiu ao longo do período e o PSD sofreu queda abrupta da primeira para segunda eleição, mantendo-se mais ou menos estável até nova queda importante em 1962, não exigiu as retificações para ser formulada, nem foi por elas modificada. A tabela do TSE (Tabela 1) revela, inclusive, que o PSD aumentou sua bancada, em números absolutos, em todas as três eleições posteriores à de 1950, o mesmo ocorrendo com o PTB. A diferença consistiu em que o PTB aumentou a sua bancada, proporcionalmente, mais do que o PSD, a sua. Deve ser acentuado, em especial, no contexto de uma queda relativa, o fato de que, entre 1958 e 1962, o tamanho da Câmara aumentou de 326 para 409 deputados, 83 cadeiras a mais $(26 \%)$, crescimento aproveitado pelo PTB, PDC, UDN, e também pelo PSD, em termos apenas absolutos no caso deste, insuficiente para mantê-lo em sua posição relativa. A hipótese contrária à tese de um declínio do PSD, com apoio na tabela do TSE, é, pois, antiga, aceita pela literatura, e continua válida, independente de qual tabela é analisada. As razões que explicariam o declínio relativo do pessedismo e o crescimento do PTB, contudo, continuam por serem descobertas.

A nacionalização de um partido, outro difícil tópico abordado por Nicolau, é importante não só pelo cálculo da amplitude de seu poder, mas sobretudo porque constitui indispensável ajuda no exercício do poder conquistado. Partidos estaduais como os da Primeira Repúbli$\mathrm{ca}, \mathrm{ou}$, no melhor dos casos, regionais, como o foram alguns durante o experimento 1945-64, não contam com informações rápidas de retorno sobre as conseqüências das políticas de governo em logradouros distantes. A perspectiva dos partidos nacionais é mais abrangente do que a estadual ou regional, e os abastece de dados atualizados sobre o que vai pelo país. A relevância do tópico é indiscutível.

Nicolau refere-se a dois autores favoráveis à tese de que os partidos brasileiros estavam se nacionalizando, no período considerado, e a outro, convencido de que somente três partidos, os maiores, se espalhavam significativamente pelo país. O método empregado por este último autor foi simples: contou o número de estados cujas contribui- 
ções somadas, em volume decrescente de votos, alcançavam $50 \%$ ou mais da votação total do partido examinado. Com isto, ficou claro que, afora os três maiores, alguns dos outros caminhavam para a estadualização, e ainda outros necessitavam de um número maior de estados para alcançar um total de votos cada vez menor.

Ao contrário de tratar o tema por inspeção direta dos dados, Nicolau preferiu adjudicar a questão por via metodológica, não obstante a verificação de que os dados retificados não alteraram os resultados obtidos com a contagem das porcentagens dispostas na tabela do TSE. A precisão buscada, no caso, não dependia das retificações nos dados, mas da aplicação de instrumento de medida mais formalizado.

Em termos simples, o índice adotado por Nicolau autoriza a inferência de que um partido será dito tanto mais nacional quanto mais a composição proporcional de sua votação total for congruente com a participação proporcional de cada estado no eleitorado total. Se o eleitorado de um estado $x$ corresponder a $5 \%$ do eleitorado total do país, então, $5 \%$ do eleitorado total do partido deverá ter sido obtido naquele estado. E assim com todo os partidos, em todos os estados.

Medidas com essa inspiração possuem apelo intuitivo, e acredito que todos os estudiosos do problema já se sentiram tentados a adotar alguma variante delas. Eu as abandonei quando deparei com situações esdrúxulas, derivadas de sua aplicação. Por exemplo: suponha um país com dois grandes distritos eleitorais, cada um deles contendo $50 \%$ do eleitorado total do país, disputados por dois partidos. Para ser nacional, conforme a medida adotada por Nicolau, os partidos devem ter um portfólio de votos congruente com a distribuição proporcional do eleitorado nacional; no exemplo, deveria ser congruente com a distribuição do eleitorado nacional entre seus dois distritos. Quantos partidos nacionais imagina o leitor essa sociedade poderia ter? -É possível que, no repente, suspeite que apenas dois. Na verdade, contudo, ou terá um partido nacional ou nenhum. Na hipótese de divisão igualitária dos distritos entre os dois partidos, cada um ficaria com $50 \%$ do eleitorado, classificando-se, ambos, como seminacionais. Se um deles obtiver $50 \%$ de sua votação total em um distrito e $75 \%$ dos votos do outro distrito, o sistema partidário contará com um partido detendo $87,5 \%$ dos votos totais contra $12,5 \%$ do outro, mas não haverá partido nacional. Somente se um partido conseguir os $50 \%$ de um distrito e mais os 50\% do outro, ou seja, $100 \%$ de cada um 
dos dois distritos, é que será considerado nacional. Medida sem valor, claro, porque não haveria outro partido no sistema. A rigor, não haveria sistema.

Estes exemplos remetem a situações extremas, uma comunidade política somente com dois distritos eleitorais, cada um com $50 \%$ dos eleitores, mas que não são impossíveis porque não são autocontraditórios (definição lógica de impossibilidade), e são válidos em um argumento analítico. Providenciar soluções aceitáveis para experiências-limite é uma das propriedades essenciais de medidas como a da nacionalização de partidos.

Supondo um país com um total de 800 votos e um estado $B$, com 200 eleitores, correspondendo a $25 \%$ do eleitorado dos mesmos 800 votos, do mesmo país, um partido recente deve contar com $25 \%$ do total de seus votos para ambicionar à condição de partido nacional. Nessa variante há um partido cujo total de votos equivale a 7,5\% do eleitorado do país, isto é, 60 votos, sendo que apenas 15 destes (25\%) devem vir do estado $B$, o que deixaria esse estado em condições de ajudar na nacionalização de mais 12 partidos nas mesmas condições, ou a 7 partidos cuja votação total alcançasse 100 votos, 25 dos quais ( $25 \%$ de 100) tendo vindo dos 185 votos restantes, descontados os 15 sufrágios conquistados pelo primeiro partido. Em resumo, um mesmo colégio eleitoral pode colaborar para a nacionalização de 13 partidos (o primeiro, que abiscoitou 15 votos, e mais 12), ou 7 partidos um pouco maiores, acrescidos de um dos de legendas menores, ou 8 partidos, digamos, grandes. Em conclusão, para um dado eleitorado, o número de partidos nacionais dependerá, de fato, da participação percentual de cada distrito eleitoral (dos estados, nos exemplos) no eleitorado total, e da variação no volume total de votos dos partidos, mas não estritamente da distribuição desses votos pelas unidades.

Tentei, posteriormente, outra possibilidade - tomando a votação total do partido (100\%), dividindo o percentual por 27 (o número de estados mais o Distrito Federal), obtendo o valor de 3,7\% de votos por unidade, independente do tamanho do eleitorado local. Idealmente, cada partido deveria obter o equivalente a 3,7\% dos votos de cada estado para que a votação total do partido refletisse eqüitativamente a contribuição de cada um deles. Mas, com esta hipotética medida, verifiquei que os partidos ficariam impedidos de tomar a decisão de, eventualmente, desejar uma distribuição nacional desequilibrada 
com o objetivo de conquistar maior poder em regiões ou unidades escolhidas. Por exemplo, o eleitorado do Estado de São Paulo, em 2002, alcançava 25.655.553 eleitores. A cota de 3,7\% que caberia hipoteticamente a cada partido equivalia a 949.255 votos do colégio eleitoral paulista. Ora, o quociente legal para a eleição de um deputado federal naquele estado, em 2002, foi estipulado pela Justiça Eleitoral em 272.931 votos $^{3}$. Na cota de 3,7\% (949.255 votos) caberiam, por conseguinte, não mais do que 3 deputados. Com uma bancada de 70 representantes na Câmara, sobrariam 67 cadeiras para os demais partidos. Com a métrica normativa de $3,7 \%$ de votos para todos os partidos que desejassem se apresentar como nacionais, o eleitorado paulista seria capaz de atender até o $22^{\circ}$ dos partidos aspirantes, contribuindo para a nacionalização de 23 partidos. Atente o leitor para o aspecto de que o número não se refere a partidos de menor expressão, mas a 23 partidos nacionais, desde que bem-sucedidos nas demais unidades da Federação, nelas obtendo os mesmos 3,7\% dos votos locais. Por outro lado, se somente existissem, digamos, 15 partidos em competição, sobrariam votos para a nacionalização de mais 8 partidos. Uma espécie de maior número de votos para menor número de partidos nacionais.

Obviamente, nenhum partido, tendo oportunidade, trocará uma cadeira de deputado a mais em São Paulo ou em vários outros estados, por outra em estados pequenos. A meta de se nacionalizar, dos grandes partidos ${ }^{4}$, não pode comprometer o cálculo pragmático de somar o maior número de votos nas unidades de maior peso na Federação. É do interesse racional dos partidos de maior porte, em conseqüência, construir uma representação nacionalmente desequilibrada que lhes proporcione, ao mesmo tempo, o máximo de peso parlamentar específico.

Depois de tentativas malsucedidas, escolhi a alternativa de estimar o grau de nacionalização dos partidos, pós-eleição, acumulando os votos por eles obtidos, a partir do maior colégio, e verificando qual o número necessário de unidades da Federação para que a soma dos votos nelas conquistados atingisse, pelo menos, $50 \%$ do total dos votos partidários: quanto maior o número de unidades da Federação necessárias para alcançar 50\%, maior o grau de nacionalização do partido. Com esta simples contagem, cheguei a conclusões sobre a nacionalização dos três maiores partidos, em curso no período 1945-62, e sobre a estadualização progressiva de vários outros. Nem os dados retificados, sem função nesta matéria, aliás, nem a medida sugerida por Nicolau, 
contrariaram, aprimoraram ou deram mais precisão a esses resultados. Concluindo: todos os 16 partidos do período 1945-62 poderiam tornar-se nacionais, conforme a métrica que usei, sem dar origem a qualquer situação partidária teratológica.

Até a publicação de The Political Consequences of Electoral Laws, de Douglas $\operatorname{Rae}^{5}$, o espetáculo de um parlamento multipartidário justificava a imagem de um instituição caótica. Tal como outros fenômenos nucleares da análise política (competição, renovação parlamentar, governabilidade etc.), a azáfama dos congressos multipartidários era indistintamente designada por dispersão, fragmentação e sinônimos, sem que se pudesse avaliar se tal dispersão crescia ou diminuía, no tempo, nem comparar dispersões, por assim dizer, de diferentes parlamentos. Não obstante a ausência de medida confiável, a literatura era pródiga em hipóteses a respeito ${ }^{6}$.

Atuais críticos do sistema partidário brasileiro sustentam tratar-se de um sistema em que os partidos são destituídos de coerência e disciplina internas, ficando seus representantes no parlamento liberados para votar como lhes aprouver. Desvencilhados do vetor causal derivado da fidelidade partidária, segue a crítica, o comportamento dos parlamentares torna-se presa de outros vetores de causalidade - a corrupção, o carreirismo, o clientelismo. Reduziu-se a ênfase na variável "dispersão", também atribuída ao multipartidarismo, e só longinquamente se aponta a possibilidade de uma crise de governabilidade, à conta da "anomia parlamentar". O argumento crítico, hoje, arma-se na seguinte seqüência: multipartidarismo inconseqüente, "anomia parlamentar" produzida pela ausência de fidelidade partidária, substituição dos programas dos partidos por fisiologismo, corrupção e carreirismo como variáveis causais do comportamento parlamentar.

Há um quarto de século, em meio à terceira ou quarta onda autoritária na Ásia, África e América Latina, o diagnóstico preferido pelos conservadores internos e analistas internacionais atribuía à irresponsabilidade do multipartidarismo os males desses continentes, incluindo sempre o sistema de representação proporcional como variável antecedente. Esquematicamente, a hipotética seqüência conectava uma elevada dispersão partidário-parlamentar, resultado do sistema proporcional, a permanente instabilidade. Interessa, aqui, registrar que os insatisfeitos com o diagnóstico, como o presente autor, esta- 
vam desafiados a demonstrar que a instabilidade, por ventura precedendo à instalação de ditaduras, não resultara de elevada dispersão anômica do eleitorado, nem do parlamento, mas de outras linhas de causalidade.

Para mim, interessado em compreender teoricamente o golpe militar de $64^{7}$, era aceitável a tese de que o multipartidarismo se seguia naturalmente ao sistema de representação proporcional, mas do multipartidarismo não se desentranhava diretamente uma crônica instabilidade política. Vetores diretamente mais relevantes, e alguns outros intervenientes, deviam estar em operação ${ }^{8}$.

Inexiste na literatura de política comparada dos anos 60 e meados dos 70, estudos que se tenham valido de um conceito e medida efetivamente acurados para comprovar o putativo estado pré-caótico em que se encontravam as populações africanas e asiáticas, propiciando as condições suficientes para intervenções militares. Medida e conceito de dispersão partidário-parlamentar estão ausentes dos trabalhos de David Apter sobre a África, de Frederik Frey sobre a Turquia, de Herbert Feith sobre a Indonésia, entre outros, até porque quase todos os sistemas se encaminharam para soluções autoritárias a partir de governos também autoritários. Mas não havia como medir, para além da etnografia dos laços tribais de parentesco, o conceito nuclear de "faccionalismo", reiteradamente apontado como estopim das guerras internas.

A América Latina, em contraposição, reivindicava um lastro histórico de períodos de governos representativos, com parlamentos multipartidários e eleições, controversas, dependendo da região, mas atendendo formalmente às imposições legais. O continente latino-americano serviu como arena para experimentos ideais-weberianos, repletos, portanto, de contrafactuais, mas contribuindo para a acumulação de dados relevantes sobre o passado-passado, sobre o passado recente e sobre o presente latino-americano. Os golpes brasileiro, argentino, chileno e uruguaio teriam entre si o explosivo denominador comum de ocorrerem em sistemas presidencialistas - Argentina, Brasil e Chile (com variante mitigada no Uruguai) - e proporcionalistas, quanto ao sistema eleitoral. Armou-se a nefasta equação, segundo os críticos, de um sistema eleitoral proporcional produzindo dispersão partidário-parlamentar, desta saindo a inevitável instabilidade política, leia-se, ditaduras. Todos os volumes publicados na década de 60 
e até, aproximadamente, meados da década de 70 acompanhavam esse diagnóstico. Nessa literatura, o denominador comum era outro: em nenhum estudo se oferecia uma forma de calcular a desordem parlamentar, nem se definia de maneira precisa, para benefício de investigações empíricas mais sofisticadas, o que efetivamente estaria sendo designado por dispersão partidária. No exterior, e em análises produzidas na segunda metade dos 70, é que a nefasta equação assume papel preponderante. Não obstante, em nenhuma publicação individual ou nas coleções editadas naquela época (entre 1975 e 1985), à exceção do livro Parties and Party Systems, de Giovanni Sartori, de 1976, o tema nuclear da fragmentação dos parlamentos é tratado como variável nobre.

Na década de 90, as expressões "fragmentação", "polarização", "crise de paralisia" foram estilisticamente incorporadas pelos especialistas em análises de sistemas eleitorais e partidários, particularmente na literatura de análise comparada. Raros, entretanto, são os autores que exploraram o tema da "fracionalização" em sua formulação rigorosa, restringindo as reflexões ao âmbito da prosa educada. No volume editado por Juan Linz e Arturo Valenzuela, The Failure of Presidential Democracy, de 1994, o longo ensaio inicial de Linz faz generoso uso da expressão "fracionalização" sem se referir, quer à medida, quer ao conceito a ela associado. E embora o volume 2, dedicado à América Latina, traga estudos sobre a Colômbia, o Uruguai e o Peru, com inúmeras remissões ao problema da fracionalização, somente Arturo Valenzuela transcreve uma tabela com valores de $F$, no caso chileno, sem explicar seu significado substantivo.

Em 1967, em The Political Consequences of Electoral Laws, Douglas Rae apresentou uma medida de fracionalização (denominada índice $F$ ) de fácil operacionalização e aplicação. De importância crucial, o conceito substantivo a que a medida se referia, fracionalização, era clara e exemplarmente definido. Fracionalização, na interpretação de Rae, significa sem ambigüidade a probabilidade de que dois deputados (ou eleitores) selecionados ao acaso em um parlamento (ou em um eleitorado), pertençam a partidos diferentes. Quanto mais alta a probabilidade, maior, evidentemente, a fracionalização. Se não houver nenhuma dispersão no parlamento (ou no eleitorado), quaisquer dois deputados (eleitores) pertencerão ao mesmo partido. O conceito tornou-se substantivamente lógico e de interpretação precisa. 
Os partidos que contribuem para o grau de fracionalização de um sistema partidário são traduzidos aritmeticamente da seguinte forma: o número de cadeiras de cada um é transformado na porcentagem do total de cadeiras ocupadas pelo partido na Câmara; e assim com todos. O somatório dessas porcentagens partidárias é igual a 100, e o segundo passo consiste em elevar ao quadrado cada uma das porcentagens. O somatório dos quadrados das porcentagens será inferior a $100 \%$, e o novo total diminuído de 1 . Assim, 1 menos o somatório dos quadrados das porcentagens de cadeiras de cada partido é igual a um número decimal - por exemplo, 0,780. Agora, o essencial significado substantivo da medida: nesse parlamento existem $78 \%$ de chances de que dois parlamentares escolhidos ao acaso pertençam a partidos diferentes. Quanto maior esse número, maior a dificuldade de selecionar ao acaso dois parlamentares que sejam do mesmo partido. De onde se segue que, quanto maior a probabilidade de que os dois selecionados pertençam a agremiações diferentes, mais fracionalizada é a Câmara.

Para encerrar o tópico do cálculo da medida, assinale-se que o valor do índice $F$ é sensível ao número de partidos e de lugares em disputa, o que quer dizer que parlamentos diferentes em número de partidos e de cadeiras podem apresentar índices $F$, indicando um deles como o mais fracionalizado quando, na realidade, não é este o caso. Em trabalho posterior, Douglas Rae e Michael Taylor apresentaram uma fórmula que permite descontar essas diferenças, tornando comparáveis parlamentos de tamanhos diferentes ${ }^{9}$. Aborda-se o problema da dispersão parlamentar em três passos: calcula-se $F$, depois se calcula o $F$ máximo possível naquele parlamento (em função do número de partidos e de cadeiras) e, por fim, divide-se $F$ por Fmax, o que nos revela quão próximo da fracionalização máxima $F$, de fato, está, e a este valor se chama de fragmentação ( Frag); quando $F$ for igual a $F$ max, terá atingido o maior valor possível e o parlamento respectivo estará convivendo com a maior fragmentação que seu tamanho, em cadeiras e número de partidos, é capaz de experimentar.

A tese adversária do sistema proporcional afirma justamente isso: que o sistema proporcional conduz o parlamento a tais níveis de fragmentação e gera crises políticas de grande envergadura, cujo desenlace costuma ser um golpe de Estado. Usando o mesmo instrumental, índices de fracionalização e fragmentação, tenho seguidamente argumentado contra esta não comprovada e catastrófica inferência. A seguir encontra-se uma tabela (Tabela 3) em que aparecem todos os Fs, 
Fmaxs e Frags, de 1946 a 1982, ou seja, cobrindo o período que vai do início das eleições pós-Vargas à última eleição sob regime militar pós-64. A tabela e comentários encontram-se no capítulo 3 da Primeira Parte de O Cálculo do Conflito, "Regimes proporcionais, multipartidarismo e estabilidade política".

Tabela 3

Fracionalização Nominal e Fragmentação do

Sistema Partidário-Parlamentar Brasileiro

(nos períodos constitucional, 1946-1962, e autoritário, 1966-1982)

\begin{tabular}{l|c|c|c|c|c|c|c|c|c|c}
\hline & $\mathbf{1 9 4 6}$ & $\mathbf{1 9 5 0}$ & $\mathbf{1 9 5 4}$ & $\mathbf{1 9 5 8}$ & $\mathbf{1 9 6 2}$ & $\mathbf{1 9 6 6}$ & $\mathbf{1 9 7 0}$ & $\mathbf{1 9 7 4}$ & $\mathbf{1 9 7 8}$ & $\mathbf{1 9 8 2}$ \\
\hline $\mathrm{F}_{\mathrm{p}}$ & 0,639 & 0,765 & 0,782 & 0,778 & 0,780 & 0,437 & 0,404 & 0,493 & 0,495 & 0,582 \\
$\mathrm{~F}_{\mathrm{mx}}$ & 0,903 & 0,920 & 0,926 & 0,919 & 0,925 & 0,501 & 0,502 & 0,501 & 0,501 & 0,802 \\
$\mathrm{~F}_{\mathrm{p}} / \mathrm{F}_{\mathrm{mx}}$ & 0,708 & 0,832 & 0,844 & 0,847 & 0,843 & 0,872 & 0,805 & 0,984 & 0,988 & 0,726 \\
\hline
\end{tabular}

Fontes: Dados brutos - TSE, Dados Estatísticos, vols. 6, 8 e 11. TSE, Diário da Justiça, 28 de novembro de 1983.

$\mathrm{F}_{\mathrm{p}}=$ Fracionalização Parlamentar; $\mathrm{F}_{\mathrm{mx}}=$ Fracionalização Máxima Possível; $\mathrm{F}_{\mathrm{p}} / \mathrm{F}_{\mathrm{mx}}=$ Fragmentação.

Posteriormente, os leitores encontrarão a razão que me obriga a transcrever o longo comentário à tabela, o que faço agora:

“[...]verifica-se que a dispersão parlamentar na Câmara dos Deputados em 1966, 1974 e 1978, só nominalmente ( $F p$ ) foi inferior ao período pré-64. Em verdade, a fragmentação $\left(F_{p} / F_{m x}\right)$ nas três eleições consideradas foi superior à do pré-64, tendo alcançado em 1978 um valor próximo do unitário. Embora lateral aqui, convém deixar registrado que não é necessariamente verdade que regimes autoritários, ou sistemas bipartidários (pois tal foi o sistema entre 1966-1978), garantam uma dispersão parlamentar efetiva (fragmentação) inferior à de regimes democráticos e multipartidários. Estes resultados são sistematicamente omitidos pelos críticos do sistema de representação proporcional, deixando subentendido que os sistemas de representação majoritária exibem, sempre e necessariamente, valores de fracionalização e fragmentação inferiores aos dos sistemas proporcionais. Este subentendido não corresponde aos fatos.

Aliás, é relevante esclarecer não só que a quantidade de partidos eleitorais não implica elevada fracionalização parlamentar, como também que o número significativo de partidos parlamentares não está associado à fragmentação. O coeficiente de correlação simples entre 
número efetivo de partidos e fragmentação, em dez eleições para o parlamento brasileiro (1946-1982), é de -0,171, indicando associação negativa, contrário ao suposto pela hipótese do majoritarismo e, ainda mais, sem significado estatístico.

A alienação eleitoral também não está associada à fragmentação. $O$ coeficiente de correlação simples para as mesmas dez eleições corresponde a 0,319 , isto é, sem significação estatística. A necessidade de proceder a testes simples e de esclarecer as relações entre essas variáveis decorre da importância que a literatura credita à fragmentação como indutora de instabilidade.

No Brasil, o que parece explicar a fragmentação é o número de partidos eleitorais. Os coeficientes de correlação para três eleições, 1954, 1958 e 1962, em 21 estados, foram, respectivamente, 0,658, 0,605 e 0,620 , todos significantes a 0,05 . Juntando este resultado ao anterior inexistência de associação entre número efetivo de partidos parlamentares e fragmentação -, segue-se que a cautela recomendaria não inferir instabilidade a partir de fragmentação, ao contrário do que faz a literatura especializada e o jornalismo político.

Quando se aponta para a suposta vulnerabilidade dos sistemas de representação proporcional, o que os advogados dos sistemas majoritários querem sugerir é bem mais do que uma relação entre representação proporcional e multipartidarismo - o que intuitivamente sabemos ser correto -, mas a existência de uma conexão entre multipartidarismo e fragmentação - o que, como se viu, não é sempre o caso - e, sobretudo, um nexo entre fragmentação e instabilidade política. Evidências internacionais, todavia, revelam não existir qualquer vínculo sistemático e consistente entre fragmentação e instabilidade. De 19 países de democracia estável, 13 apresentam um índice médio de fragmentação acima de 0,80 , que é o patamar em que se encontra o Brasil. [...] A menos que se negue a esse conjunto de países o usufruto da estabilidade democrática, deve-se concluir que as relações entre fragmentação e instabilidade não são tão simples quanto às vezes se pretende. Se o fosse, deveríamos ser capazes de explicar a crise de 1964 em função do elevado coeficiente de fragmentação parlamentar resultante das eleições ocorridas dois anos antes, em 1962. Leitura atenta da Tabela 3-1 permite desde logo a formulação de duas perguntas: por que dois anos depois das eleições de 1962 e, não, quatro anos após as eleições de 1958? Ou por que não em 1958, quatro anos depois de transcorridas as eleições de 1954?" (Santos, 2003:100-103). 
A longa citação foi motivada pela nota 16 do artigo de Nicolau, que diz o seguinte: "Na primeira parte do livro, apesar dos diversos cálculos, Santos (2003) não faz comentários sobre as tendências da fragmentação no plano nacional". Adiante me ocuparei do resto da nota de Nicolau. Mas, desde logo, não sei como interpretar o que Nicolau indica com "plano nacional". Todo o capítulo 3 mencionado, no qual se encontra o trecho acima transcrito, e mais os comentários não só aos dados nacionais, mas em comparações internações (ver Tabela 3.2, p. 102 do Cálculo, "Fragmentação parlamentar média em 19 democracias representativas e o Brasil"), não se destinam, prioritariamente, a outro objetivo senão o de refutar a tese de que os sistemas proporcionais nacionais, conduzindo as nações ao multiparidarismo, terminam por levá-las a crises nacionais ${ }^{10}$. Não só trato o problema tomando a Câmara dos Deputados como unidade de análise (na Tabela 3.1, citada), como, depois, tendo como unidade de análise as bancadas estaduais no plano nacional, isto é, na Câmara dos Deputados, calculo os índices de fracionalização, de fracionalização máxima e de fragmentação de todos os estados na Câmara, em Brasília, para as eleições de 1954, 1958 e 1962 - Tabela 5.2, "Fracionalização e fragmentação parlamentares das bancadas estaduais na Câmara dos Deputados - eleições de 1954, 1958, 1962" -, tabela que toma as páginas 148 e 149. O contexto é o do debate sobre se os pequenos partidos estavam ou não se nacionalizando, e, dando início à discussão, comento, no primeiro parágrafo que segue à tabela:

“O que se observa na coluna da fragmentação (a última), que indica a fracionalização tomada como proporção da fracionalização máxima possível, e que depende do número de partidos - por isso escolhi esse indicador - é que, em apenas quatro casos (ES, PA, PI e SP), se revela crescente fragmentação do sistema. Em praticamente todos os demais, à exceção de Acre, Paraíba e Bahia (decréscimo consistente) o valor da fragmentação oscila erraticamente." (idem:149-150)

A continuação da nota 16 de Nicolau, depois de sustentar que não trato do problema nacionalmente, complementa: "Para os estados, o autor afirma que os índices de fragmentação ( $\mathrm{F}$ como proporção do $\mathrm{F}$ máximo) oscilam" (:104). Tenho dúvidas se Nicolau se refere aos estados em sua representação nacional ou se em suas Assembléias Legislativas. Tendo em vista a declaração anterior, a de que não trato o problema em "plano nacional", se eu não transcrevesse o texto das páginas 149-150 o leitor suporia que o meu comentário citado por Nicolau 
se refere às assembléias estaduais. Por outro lado, ao se lembrar de minha tese de fragmentação crescente, ficaria equívoca minha assertiva de que em alguns estados ela oscilava. Para um leitor desatento, a conclusão provável é a de que eu estaria ora afirmando que a fragmentação cresce, ora que oscila. Minhas duas inferências referem-se, todavia, a unidades de análise diferentes: uma tomando a Câmara como sujeito, outra, as representações estaduais individualizadas nessa Câmara.

Esperando haver sanado o pequeno embaraço do texto do artigo "Velhas Teses, Novos Dados", cabe examinar o tratamento dado por Nicolau ao importante tema da fracionalização, do qual se espera análises proporcionadas pelas retificações promovidas na tabela do TSE, e contrárias às teses em circulação na disciplina.

A abordagem de Nicolau ao tópico inicia-se pela observação de que, não estando disponíveis, à época, as retificações efetuadas por ele na estatística, Olavo Brasil de Lima Junior, Antônio Lavareda e eu chegamos a resultados distorcidos (:96). Não obstante, à página 98 comenta o seguinte: "É interessante salientar que, apesar de mostrar dados semelhantes que evidenciavam estabilidade na dispersão de poder parlamentar, Santos $(2003: 77,99)$ chegou a conclusões diferentes". De acordo com o princípio do terço excluído, é evidente que não posso haver analisado a dispersão eleitoral apoiado em dados distorcidos, mas que seriam, ao mesmo tempo, semelhantes aos por ele obtidos. Entendo, porém, que a frase indica a surpresa de Nicolau com o que lhe pareceu um erro crasso. Pois bem, este é um excelente contexto para avaliar a contribuição das retificações de Nicolau à análise da fracionalização do sistema partidário brasileiro entre 1945 e 1962.

A resposta concisa à observação de Nicolau é a seguinte: a razão pela qual chegamos a conclusões diferentes se deve a utilizarmos bases de dados diferentes (pouca relevância), buscando respostas a questões diferentes (média relevância), com métodos parcialmente diferentes (muita relevância). Esclarecendo logo as duas primeiras diferenças: eu utilizei as estatísticas do TSE, enquanto Nicolau, as retificadas, as quais, segundo informa, discrepam largamente das do TSE (mas isto, como mostrei, não é exato); meu objetivo, reiterado nas várias páginas de meu livro a que Nicolau remete, era o de criticar a tese de que o sistema de eleições proporcionais leva à instabilidade política e a golpes de Estado, pela via do multipartidarismo, ao passo que o objetivo 
de Nicolau é triplo: rejeitar hipóteses da literatura sobre a evolução da força dos partidos, ao longo das eleições no período 1945-62; rejeitar outras sobre possíveis avanços na nacionalização dos partidos; e, finalmente, reconsiderar profundamente teses correntes sobre a fracionalização do sistema partidário brasileiro. Esclarecidas as diferenças entre as respectivas bases de dados e objetivos das análises, resta a diferença de metodologias.

Informo ao leitor, preliminarmente, que, não obstante discutir o problema da dispersão, ou fragmentação partidária (parlamentar e eleitoral), Nicolau não transcreve uma só tabela de fracionalização ou fragmentação. Todas as suas tabelas, com respeito à fragmentação, trazem, na verdade, número efetivo de partidos, mas nenhum índice F, Fmax ou Frag. Por isso, transcrevi minha Tabela 3.1 e comentários (aqui exposta como Tabela 3). Duas observações: a primeira é que Nicolau não está usando o conceito de "fragmentação" tal como existe na literatura pertinente, mas na forma estilisticamente livre em que o transformaram alguns analistas, sinônimo de "efetivo número de partidos" ou de presidentes ${ }^{11}$. A segunda observação refere-se ao equívoco a que o leitor pode ser conduzido ao concluir que o efetivo número de partidos é uma medida de fragmentação. Não é. É uma medida extremamente obscura, sem nenhuma interpretação substantiva autorizada.

Nicolau registra que ora utilizo a expressão "efetivo número de partidos", ora a substituo por "número efetivo de partidos". Está correto, utilizo ambas como variação estilística, posto que significam a mesma coisa: o adjetivo "efetivo" qualifica o mesmo substantivo "número", independente da ordem em que se coloca o adjetivo em relação ao substantivo. Nos artigos e livros que adotam a medida, a expressão invariavelmente usada é "efetivo número de partidos", como se qualquer outra designação fosse incorreta. As duas que uso são semanticamente equivalentes. Grave falha metodológica é aquela cometida precisamente pelos que atribuem monopólio de significado a "efetivo número de partidos", a saber, a insinuação de que "número" se refere a partidos efetivos, sugerindo que aquele seria o número de partidos que efetivamente contam na respectiva Câmara ou eleitorado. A distinção é perfeitamente conhecida por todos os profissionais, inclusive pelos inventores da medida, mas quase todos contribuem para a 
confusão, inclusive os inventores da medida, interpretando os resultados como se designassem partidos efetivos.

Em "The 'Effective' Number of Parties", Markku Laakso e Rein Taagepera (1973:3-27) aspeam a expressão "efetivo" e expressamente advertem que não se trata de "partido efetivo". Considero obscuro, rejeitada essa interpretação, qual seja, então, o significado de "número efetivo" ou "efetivo número", tanto faz. A confusão é promovida logo a seguir, no exemplo em que a medida é aplicada ao parlamento britânico, em duas oportunidades, registrando a existência de 2,4 e 2,0 "efetivos números de partidos", mas tratados como se fossem 2,4 e 2,0 "partidos efetivos". A expressão mesma, literalmente, "effective parties", é empregada no exemplo finlandês imediatamente a seguir (idem:4).

Há problemas computacionais sérios (não o cálculo, mas a interpretação dos passos) na medida, mas não é o mais importante aqui ${ }^{12}$. Relevante são as razões que abalam o "efetivo número de partidos" como indicador de fracionalização ou de fragmentação.

a) o efetivo número de partidos é derivado de $F$, e sua fórmula, ${ }^{1} / 1$-F, substitui uma probabilidade de direta e não ambígua interpretação, que é $F$, por fracionários do tipo 2,4, 1,8, ou, mesmo, 5,0 efetivos números de partidos de impossível interpretação substantiva. Não há como identificar os "partidos efetivos", a partir do "número efetivo de partidos", nem se é capaz de deduzir proposições probabilísticas, como em $F$, sobre os partidos aos quais os membros do parlamento estariam filiados ${ }^{13}$.

Os inventores da medida apresentam uma definição clara de seu significado, que reza assim: "O efetivo número de partidos é o hipotético número de partidos de igual tamanho que teria o mesmo efeito total na fracionalização do sistema, tal como o têm os partidos reais de tamanhos desiguais"14 (ibidem, ênfases no original). Não conheço argumento lógico, somente a coincidência estatística apresentada pelos usuários $\mathrm{de}^{1} / 1$-F, que dê a razão da nova medida. Por isso, formulei um argumento mais rigoroso do que a prosa dos inventores e seguidores na expectativa de que o leitor compreenda o que significa o efetivo número de partidos, excluída a interpretação de que não se refere a número de partidos efetivos. Os passos do argumento são os seguintes: 
1) Para qualquer valor de $F$, derivado de uma distribuição de $n$ cadeiras por $N$ partidos, há pelo menos uma outra distribuição de $n$ por $N$, além da que gera o $F$ máximo (quando $F$ é igual a $F$ máximo), que satisfaz a equação $F=1-\left(\Sigma \% c^{2}\right)$.

2) Dados os valores reais de $F, n$ e $N$, existe um número abstrato $N^{\prime}$, diferente de $N$, caracterizado por uma distribuição igualitária de $n$ entre eles, dando origem a um $F^{\prime}$ igual ao $F$ gerado pela distribuição original, desigual, de $n$ por $N$. Esse abstrato número de partidos $N^{\prime}$ é induzido dos valores de $F, n$ e $N$ reais, e não pode ser deduzido de nenhuma distribuição hipotética da qual não se conheça, por implicação, o valor real do índice $F$ da distribuição.

O índice NEP (número efetivo de partidos) constrói-se como um contrafactual aritmético, dispondo, em suas premissas, condições contrárias aos fatos: como todo contrafactual, se existisse um número hipotético de partidos $N^{\prime}$, e se cada um deles controlasse o mesmo número de cadeiras $n$, então, o índice de fracionalização desse hipotético parlamento $\left(F^{\prime}\right)$ viria a ser igual ao $F$ real do parlamento real.

A tradução mais generosa da definição de $N E P$ e suas derivações é, pois, a seguinte: dado um $F$ real, para uma desigual distribuição de $n$ entre $N$, quantos partidos, entre os contidos em $N$, seriam necessários para que, na hipótese de que $n$ fosse igualitariamente distribuído entre eles, o segundo $F$, derivado da nova distribuição (igualitária), fosse semelhante ao $F$ real? O quebra-cabeça aritmético é interessante, pois uma distribuição igualitária de $n$ lugares por $N$ partidos produz um $F$ variável, à medida que $N$ varia. Distribuir igualitariamente o total de cadeiras por 5,7 ou 8 partidos produzirá $F$ diferentes para cada valor de $N$, se mantido $n$ constante. Como exercício aritmético, e tão-só aritmético, sem modelo que estabeleça a relação entre suas entidades abstratas e as entidades reais, o número efetivo de partidos pode ser descoberto conforme os passos a seguir:

Dados $N$ (número de partidos) e $n$ (número de cadeiras), qual será o $F$ derivado de uma distribuição igualitária de $n$ por $N$ ? - A resposta existe, compromete a originalidade do $N E P$, e é a seguinte: a distribuição máxima de $n$ cadeiras por $N$ define de maneira exata, e única, a distribuição igualitária desse sistema (que é o cálculo formulado por Rae e Taylor). O cálculo de fracionalização máxima, como se viu, independe do valor real de $F$, sendo suficiente a informação sobre $n$ e $N$. Embo- 
ra duas distribuições diferentes possam dar origem ao mesmo valor de $F$, a relação entre fracionalização máxima e Fébiunívoca. Não existe nenhuma outra distribuição de $n$ por $N$ cujo valor $F$ também possa ser idêntico a Fmax. Para qualquer valor de $n$ e $N$, pelo menos duas distribuições diferentes de $n$ por $N$ podem gerar o mesmo valor de $F$. O valor de Fmax, ao contrário, só é compatível com uma distribuição: aquela que dá origem ao próprio $F m a x^{15}$. Entre os partidos incluídos em um $N$ real, e dados $n$ e $F$, também reais, não é difícil calcular um $N E P$, não havendo, entretanto, nenhuma possibilidade de identificar, entre os partidos reais, quais aqueles que, estipulados pelo NEP, produziriam o mesmo $F$ real, desde que $n$ fosse igualitariamente distribuído entre eles. Quais os 4 partidos, por exemplo, que seriam escolhidos entre os 16 do período 1945-62? - PSD, PTB, UDN e..., PR? PL? PSP? PDC? E quando o efetivo número de partidos for igual a 4,3, por quais 4,3 partidos efetivos, isto é, reais, o número de cadeiras será eqüitativamente distribuído? O mundo da fracionalização real é distinto do mundo da fracionalização contrafactual, e não é deste que se deduz aquele, mas ao contrário, é do mundo da fracionalização real (uma efetiva distribuição existente) que se induz um contrafactual aritmético. Por isso, o NEP não mede fracionalização, nem mesmo variação no número de partidos. É medido (limitado) por eles e pelo número de cadeiras a distribuir.

Trata-se, portanto, ${ }^{1} /$ 1-F, de uma transformação aritmética contrafactual que, a partir de uma distribuição real desigual, que se expressa nos quadrados dos diversos valores percentuais das cadeiras de cada partido, chega ao número de partidos que, com uma distribuição eqüitativa das cadeiras, geraria o mesmo $F$ real. $F$ mede a dispersão real, o que é absolutamente relevante para o cálculo dos custos de transação na formação de coalizões, tendo em vista o significado probabilístico substantivo de $F$ - perdido na transformação contrafactual aritmética -, enquanto o NEP não mede o número de partidos reais que produzem efeito no sistema, não apenas em índices, nem o número abstrato em que se expressa pode ser distribuído entre os partidos reais. Quais são os quatro partidos que produziriam o $F$ real, dispensando-se os demais, em um conjunto de 12, 13 partidos. A propósito, o NEP que acompanhou todo o período 1945-62 variou de 4 a 4,3: quais 4 entre os 16 do sistema partidário brasileiro? De um contrafactual aritmético nada pode ser derivado substantivamente sobre o mundo extra-aritmético. De $F$ real decorre a probabilidade de que dois parla- 
mentares (ou eleitores) selecionados ao acaso pertençam a partidos diferentes.

b) Ainda enumerando as limitações do NEP, diferentes distribuições de cadeiras no parlamento podem dar lugar ao mesmo índice $F$, levando, claro, ao mesmo efetivo número de partidos. Se o número de cadeiras e de partidos variarem, contudo, o índice $F$ pode não captar a variação subseqüente na divisão das cadeiras pelos partidos, indicando dois perfis diferentes de $n$ (número de cadeiras) por $N$ (número de partidos) e, portanto, com fragmentações realmente diferentes, como se possuíssem a mesma dispersão original. Obviamente, o "efetivo número de partidos" acompanha o índice nesta reconhecida vulnerabilidade.

c) Ignora-se a relação entre o índice $F$ e o efetivo número de partidos, embora este seja uma derivação daquele. Por exemplo: a quanto equivale uma variação em $F$ na tradução de ${ }^{1}$ /1-F (não esquecendo, esta é a fórmula do efetivo número de partidos)? quantos valores diferentes de $F$ podem conduzir ao mesmo número efetivo de partidos?

Não obstante essas objeções, também apresento, em meu livro, resultados relativos ao efetivo número de partidos, mas, desde a primeira tabela em que aparecem, encontra-se a seguinte nota de rodapé: "utilizo aqui esta medida [a do número de partidos] atendendo ao convencional da literatura contemporânea, apesar de algumas limitações importantes que a caracterizam" (Santos, 2003:77, nota 14). Nicolau, ao contrário, sustenta, em sua nota 17 , que "O número efetivo de partidos, proposto por Markku Laakso e Rein Taagepera, mensura o peso relativo de cada partido nas eleições ou no Legislativo" (:104). Como mostrei, a afirmação é, tecnicamente, improcedente.

Suprirei a lacuna de uma efetiva, necessária e omitida análise da fracionalização da tabela retificada por Nicolau depois de dar um exemplo numérico do equívoco a que os estudiosos se expõem quando tomam o ininterpretável efetivo número de partidos por confiável indicador de fracionalização. Considere a hipotética tabela abaixo na qual se encontram: os anos eleitorais, o atribuído valor que $F$ teria alcançado naqueles anos e, finalmente, o valor do NEP derivado da série hipotética: 
Tabela 4

Evolução de F e do NEP* (tabela hipotética)

\begin{tabular}{c|c|c}
\hline Anos Eleitorais & F & NEP* \\
\hline 1945 & 0,750 & 4 \\
1950 & 0,752 & 4 \\
1954 & 0,754 & 4 \\
1958 & 0,756 & 4 \\
1962 & 0,758 & 4,1 \\
1966 & 0,760 & 4,1 \\
1970 & 0,762 & 4,2 \\
1974 & 0,764 & 4,2 \\
1978 & 0,766 & 4,2 \\
1982 & 0,768 & 4,3 \\
1986 & 0,770 & 4,3 \\
\hline
\end{tabular}

* Número efetivo de partidos.

Observe-se que, de 1945 a 1966, $F$ passou de 0,750 a 0,760, variação que pode indicar muita ou pouca coisa quanto ao potencial de coalizões parlamentares, dependendo dos movimentos partidários que explicam o aumento da dispersão. Mas aponta, com certeza, que algo mudou e merece investigação minuciosa. Duas distribuições diferentes podem originar o mesmo valor de $F$, como se sabe. É impossível, contudo, que uma só distribuição gere mais de um valor do índice. Por isso, variações no valor de $F$ asseguram que houve alteração nas divisões originais de $n$ por $N$.

$\mathrm{Na}$ última coluna (NEP) encontram-se os valores de ${ }^{1} / 1-\mathrm{F}$, calculados sobre a coluna dos $F$, para o mesmo período (1945-66), correspondendo a um intervalo de 21 anos e 6 medidas $F$, tendo estas crescido a quantidades uniformes. Verifica-se que o cálculo produziu o mesmo não interpretável número 4, de 1945 a 1958, alterado para 4,1, estável, nas duas medidas seguintes com diferentes Fs. E assim continua a série de tal modo que, tanto quanto se pode perceber, permanece desconhecida a relação sistemática entre valores variáveis de $F$ e esses obscuros e extraordinariamente estáveis números efetivos de partidos. Pela tabela hipotética, mas perfeitamente verossímil (veja, adiante, os cálculos para a tabela retificada de Nicolau), em 41 anos e 11 medidas de fracionalização, enquanto os valores de $F$ passaram de 0,750 para 0,770, de 1945 a 1986, o número efetivo de partidos variou, entre os ex- 
tremos, de 4 para 4,3 partidos. Em minha opinião, a validade de qualquer inferência substantiva, não-lógica, a partir desses números é bastante precária.

Compreendo, portanto, porque Nicolau evitou avaliar o impacto de suas retificações sobre a real fracionalização do sistema partidário brasileiro, no período 1945-62, limitando-se a expor valores de um indicador claramente inferior ao $F$ de Rae. É de todo interesse que esses cálculos de $F$ sejam feitos, entretanto, de modo estritamente subordinado ao ângulo estipulado por Nicolau, ou seja, o de decidir se as modificações por ele introduzidas nas estatísticas eleitorais do período afetaram, como ele afirma que teriam afetado, as análises até então produzidas, em particular aquelas relativas à fracionalização do sistema.

Desde 1962 até a eleição de 2002, o Brasil experimentou outras dez eleições gerais e não há motivo para que não se transcreva a série histórica completa do índice $F$, desde 1950, excluindo-se 1945 por seu caráter atípico. O gráfico abaixo reproduz a evolução da fracionalização do sistema partidário-parlamentar no Brasil, de 1950 a 2002:

Com o transcorrer do tempo, ficaram ressaltados dois movimentos: o da queda abrupta em $F$, logo depois do golpe militar, da repressão

\section{Gráfico 1}

Fracionalização Brasil - Câmara dos Deputados

Com Aproximação ( 3 casas)

(1950-2002)

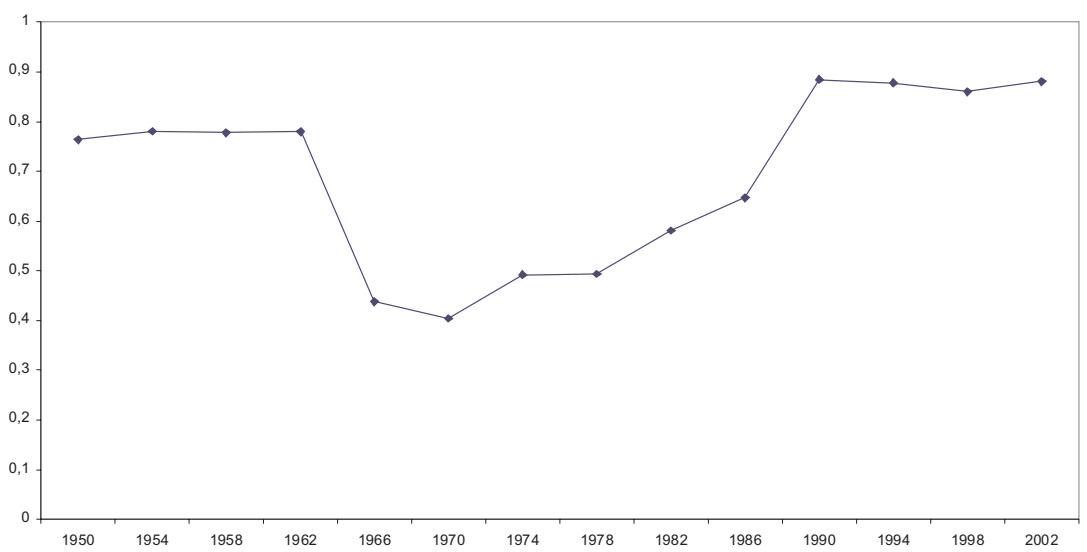


partidária e das cassações; e o da retomada do crescimento do valor do índice, ainda na ditadura (a partir de 1970), até a eleição de 1990, permanecendo relativamente estável nas três eleições subseqüentes.

Observo, de imediato, que a tese da instabilidade política associada ao multipartidarismo, que resultaria do sistema de eleição proporcional, perde qualquer vestígio de verossimilhança. Os valores do índice têm variado por razões ainda não estudadas completamente ${ }^{16}$, mas suas conseqüências estão bastante circunscritas à dinâmica das coalizões parlamentares, sem que, até agora, tenha havido ameaça à estabilidade política do país por conta do putativamente esgarçado sistema partidário. Vale enfatizar ainda que os valores de $F$, pós-86, são superiores aos do pré-64. O temporário esquecimento da tese que associava sistema proporcional à instabilidade política encontra, no gráfico acima, parte de sua explicação, e rejeição, sem prejuízo de que alguns brasilianistas continuem produzindo trabalhos especulativos de escasso valor comprobatório com base nessa hipótese.

Trazendo a matéria para os números do período 1945-62, apresentei em O Cálculo (Tabela 3.1) os dados já reproduzidos aqui e, em outra passagem do volume (:245), listei os índices $F$ com dois dígitos apenas. Esta segunda versão é apenas indicativa porque a terceira casa decimal costuma introduzir diferenças em índices até então homogêneos. Com aproximação nas decimais, a tabela da p. 45 de $O$ Cálculo, apresentaria a seguinte sucessão: $0,71,0,83,0,84,0,84$ e 0,84 . Com três casas decimais a série é a que está disposta na Tabela 3.1. Entre 1945 e 1962, F variou de 0,708 a 0,843; entre 1950 e 1962 - dispensando 1945 por atipicidade - o índice, ainda assim, variou entre 0,832 e 0,843 . Não há dúvida de que entre os dois pontos extremos $F$ variou para mais. Desagregadamente, verifica-se que o índice aumentou de 1945 a 1954, permanecendo, depois, mais ou menos estável.

Computado como proporção do máximo possível, ou seja, como fragmentação, o índice é crescente, à exceção da própria eleição de 1962, e próximo do máximo desde 1954, aí, então, inclusive a de 1962. Se tomamos como base a variação entre os extremos, cabe sublinhar o visível aumento no valor da Frag. Se tomamos como base os índices desagregados por eleição, cabe apontar aumento seguido de estabilidade a níveis próximos do máximo. Em qualquer caso, os resultados permitem que se afaste a hipótese de que instabilidade se segue à fragmentação. Fosse a hipótese correta, não se entenderia por que a insta- 
bilidade não ocorreu em 1958, e sim depois de 1962, nem por que, em comparações internacionais, ponderável número de países de indiscutível estabilidade apresentaram índices médios de $F$ bem superiores ao do Brasil (Santos, 2003:102, 247).

A seguir, o leitor encontrará três tabelas, cada uma delas apresentando os resultados dos cálculos que fiz dos índices de fracionalização, fracionalização máxima e fragmentação da tabela retificada por Nicolau, ao lado dos índices calculados sobre as estatísticas do TSE.

Tabela 5

\begin{tabular}{c|c|c}
\hline \multicolumn{3}{c}{ Fracionalização } \\
(F) \\
\hline Ano & Nicolau & TSE \\
\hline 1945 & 0,632 & 0,639 \\
1950 & 0,757 & 0,765 \\
1954 & 0,769 & 0,782 \\
1958 & 0,773 & 0,778 \\
1962 & 0,779 & 0,780 \\
\hline
\end{tabular}

Tabela 6

\begin{tabular}{c|c|c}
\hline \multicolumn{3}{c}{$\begin{array}{c}\text { Fracionalização máxima } \\
\text { (Fmax) }\end{array}$} \\
\hline Ano & Nicolau & TSE \\
\hline 1945 & 0,892 & 0,903 \\
1950 & 0,920 & 0,920 \\
1954 & 0,912 & 0,926 \\
1958 & 0,919 & 0,919 \\
1962 & 0,925 & 0,925 \\
\hline
\end{tabular}

Tabela 7

\begin{tabular}{c|c|c}
\hline \multicolumn{3}{c}{$\begin{array}{c}\text { Fragmentação } \\
\left(\begin{array}{c}\mathrm{F} / \\
\text { Fmax }\end{array}\right)\end{array}$} \\
\hline Ano & Nicolau & TSE \\
\hline 1945 & 0,708 & 0,708 \\
1950 & 0,823 & 0,832 \\
1954 & 0,843 & 0,844 \\
1958 & 0,841 & 0,847 \\
1962 & 0,842 & 0,843 \\
\hline
\end{tabular}

Fontes: TSE, vários volumes e Nicolau (2004); elaboração Leex.

Os índices de fracionalização $(F)$ da tabela de Nicolau, de que teria permanecido surpreendentemente estável, mesmo com a exclusão de 1945, crescem consistentemente de 1950 a 1962, contra a opinião de Nicolau, passando de 0,757 a 0,779 , embora o efetivo número de partidos permaneça entre 4 e 4,5. Os da tabela do TSE, à exceção de 1958, são iguais aos da tabela retificada, se tomados somente com dois dígitos, e bastante próximos, em 1958 e 1962. O índice de fragmentação cresce até 1954, recua ligeiramente em 1958, e volta a crescer em 1962. Os números da coluna do TSE crescem em todos os anos, caindo ligeiramente em 1962, exatamente no ano em que o índice de fragmentação da tabela retificada volta a crescer, embora ligeiramente. Nenhum impacto relevante, portanto, na investigação dos graus de fracionalização do sistema partidário brasileiro, à conta das informações retificadas. A fracionalização máxima dependendo do número de partidos e do número de cadeiras, mas não da distribuição delas, só difere na tabela retificada da tabela do TSE nos dois anos em que, em razão da distribuição de cadeiras antes em "coligações", altera o número de partidos na tabela de Nicolau. Até porque, número de cadeiras e nú- 
mero de partidos, variáveis nobres no cálculo da fragmentação, nada têm a ver com as retificações operadas por Nicolau. Em minha opinião, ficou demonstrado, pelo correto cálculo de fracionalização, que as retificações nos dados primários não trouxeram subversões de monta a alterar a base de dados nem os cálculos que autorizam a análise da fracionalização do sistema partidário-parlamentar brasileiro apoiada nas estatísticas do TSE.

Finalmente, Nicolau não fornece a necessária distinção entre fracionalização e estabilidade/instabilidade. É de fácil compreensão que, tanto aumento quanto diminuição do índice $F$, ou de Frag, são perfeitamente compatíveis com a estabilidade relativa de alguns partidos. E vice-versa: instabilidade nas votações de alguns partidos pode, não obstante, dar origem a um $F$ de valor constante. Ou seja, em sentido exato, uma coisa é a estabilidade na votação de um partido, outra, o grau de dispersão do sistema de que faz parte. Na falta da distinção, pela submissão ao obscuro efetivo número de partidos, pode-se acabar provocando uma sucessão de raciocínios desconexos.

Desafortunadamente, não fui capaz de tratar com brevidade os tópicos do artigo de Nicolau. Não são triviais, nem é recomendável que se os apresente como tais. Procurei transformar este artigo em exercício de esclarecimento conceitual e metodológico de expressões recorrentes que, com freqüência, são empregadas de forma estritamente literária. Espero ter ficado claro, entretanto, que nenhum resultado de pesquisa é descartável. Um projeto fracassado deixa como saldo positivo certo acréscimo no estoque das proposições equivocadas, o que nos permite rejeitá-las, e esclarecimentos onde havia dúvidas. No caso, os estudiosos podem utilizar com segurança as estatísticas eleitorais do TSE, ou as retificadas por Nicolau, posto que nenhuma das teses relevantes em circulação na academia foi por estas abalada.

(Recebido para publicação em outubro de 2004) (Versão definitiva em novembro de 2004) 


\section{NOTAS}

1. Axioma refere-se a uma proposição evidente por si mesma; um postulado é um protocolo mediante o qual se aceita como premissa legítima uma proposição não demonstrada.

2. Aumentando o número de eleitos via coligações seria natural que se descobrisse número bem mais elevado de discrepâncias. De fato, os dois casos especialmente anotados ocorreram justamente no ano em que o número de eleitos, via coligação, foi o maior de toda a série. A porcentagem de eleitos via coligação, discriminada por partidos e eleições, encontra-se na Tabela 5.8, de O Cálculo do Conflito (Santos, 2003:159).

3. Os quocientes legais e operacionais (eleitorado menos abstenção, votos brancos e nulos) para todos os estados, em todas as eleições, até 1998, encontram-se no capítulo 2 de Santos (2002:55-64).

4. A estratégia dos médios e pequenos partidos é distinta. Eles se concentram nos estados onde têm mais chances, antes que dispersar esforços e recursos materiais.

5. A $2^{\mathrm{a}}$ edição, de 1971, traz novo e importante capítulo, o de número 10, indispensável à compreensão das teses de Rae.

6. Por necessidade de investigação sobre competitividade eleitoral e sobre renovação parlamentar fui levado a construir dois índices: ver "Da Oligarquia à Poliarquia Competição Eleitoral e Processos Não-Encarceráveis" (Santos, 1997a), sobre competitividade; e "Da Poliarquia à Oligarquia? - Eleições e Demanda por Renovação Parlamentar" (Santos, 1997b), sobre renovação parlamentar. Em outro trabalho, preferi apresentar um modo mais simples de indicar a competitividade, mediante o número médio de candidatos por vaga. Cf. Regresso - Máscaras Institucionais do Liberalismo Oligárquico (Santos, 1994), reproduzido em Décadas de Espanto e Uma Apologia Democrática (Santos, 1998). Recentemente, em livro com o sugestivo título de The Deadlock of Democracy in Brazil, Barry Ames (2001) usa a medida mais rigorosa. Na p. 116, nota 17, dá a fórmula de cálculo do índice, mas não registra a fonte.

7. Fiz a análise da conjuntura do período em Quem Daráo Golpe no Brasil (Santos, 1961) e em Reforma contra Reforma (Santos, 1963).

8. Simplificadamente, atribuo à paralisia decisória do Executivo e da Câmara dos Deputados a responsabilidade imediata pela crise de Estado que antecedeu o golpe de 64. Essa paralisia, por sua vez, resultou de um processo de fragmentação das coalizões na Câmara (três coalizões de veto e nenhuma de governo), resultado e vetor coadjuvante na radicalização do período 1961-64. O argumento completo encontra-se em O Cálculo do Conflito (Santos, 2003).

9. A fracionalização máxima é calculada pela fórmula: $N(n-1) / n(N-1)$, onde $N$ representa o número de cadeiras e $n$ designa o número de partidos parlamentares (cf. Rae e Taylor, 1970:26). O valor alcançado indica qual seria o valor de $F$ se as cadeiras estivessem igualmente divididas por todos os partidos.

10. Calcular índices médios de fracionalização em assembléias de um mesmo país serve como ponto de referência, mas sua utilização deve ser cautelosa, tendo em vista a propriedade do índice de que duas distribuições diferentes podem originar o mesmo valor de $F$. Comparar índices médios de vários países exige redobrados cui- 
dados e as conclusões devem ser tentativas. Mas calcular índices médios de fracionalização ou de efetivo número de candidatos presidenciais (!), para um conjunto de países, cada um deles com seu índice médio, é uma incompreensível extensão metodológica (cf. Carey, 1997:75, Tabela 3).

11. Veja a nota 10 relativa a trabalho de John Carey.

12. Trato extensamente das vulnerabilidades da medida proposta por Laakso e Taagepera em Santos (1999), que fiz circular entre alguns colegas.

13. Farrell (1997:146-147, Tabela 7.1) lista valores do efetivo número de partidos para eleições em 37 países, variando de 1,92, nos Estados Unidos, em uma média de 23 eleições, a 5,1, média de 11 eleições na Suíça.

14. A condição hipotética de igual tamanho é repetida no capítulo 8 de Seats \& Votes (Taagepera e Shugart, 1989), e logo esquecida, passando os autores a sugerir que o $N E P$ hipotético e $F$ real são a mesma coisa, com a vantagem, segundo os autores, de que o NEP seria mais fácil de calcular. A afirmação é claramente descabida, pois que, em ambas, o passo principal é o mesmo somatório dos quadrados das porcentagens dos partidos. Arend Lijphart (1994:69) repete o mesmo juízo depois de haver afirmado, à p. 68, o seguinte: "The effective number of parties carries the same information as the Rae index of party fractionalization". Esta surpreendente declaração é incorreta. Caso ambos trouxessem a mesma informação, do número efetivo de partidos poderiam ser derivadas probabilidades sobre coincidências ou contrariedades de partidos a que os parlamentares pertencem - e isto é absolutamente impossível de ser calculado - e, por outro lado, também não seria permitida a menção a número de partidos, do qual o $F$ de Rae é completamente independente, exceto quando $\mathrm{F}=\mathrm{F}_{\max }$.

15. E pela essencial razão de que $F \max$ mede o valor de $F$ quando $n$ e $N$ são distribuídos igualitariamente. A proporção $\mathrm{F} / \mathrm{Fmax}$ indica justamente qual a distância a separar o valor de $F$ da distribuição igualitária entre cadeiras e partidos.

16. Arturo Valenzuela em seu artigo na coletânea de Juan Linz e ele próprio, já citada, "Party Politics and the Crisis of Presidentialism in Chile", único que apresenta índices de fracionalização conforme definição e método ortodoxos, procede a alguns testes e verifica a não associação entre índices de fracionalização e as variáveis ecológicas de praxe (cf. Linz e Valenzuela, 1994:104, Tabela 6.4).

17. As diferenças entre os índices de fracionalização máxima das tabelas do TSE e a retificada por Nicolau deveram-se, principalmente, à diminuição do número de partidos computados na tabela do TSE, associados a coalizões, e que desaparecem na tabela de Nicolau. 


\section{REFERÊNCIAS BIBLIOGRÁFICAS}

AMES, Barry. (2001), The Deadlock of Democracy in Brazil. Ann Arbor, The University of Michigan Press.

CAREY, John. (1997), "Institutional Design and Party Systems”, in L. Diamond, M. F. Plattner, Yun-han Chu e Hung-mao Tien (eds.), Consolidating the Third Wave Democracies - Themes and Perspectives. Baltimore, The Johns Hopkins University Press.

FARRELL, David M. (1997), Comparing Electoral Systems. London, Prentice Hall.

LAAKSO, Markku e TAAGEPERA, Rein. (1973), “The 'Effective' Number of Parties: A Measure with Application to West Europe". Comparative Political Studies, vol. 12, no 1 .

LIJPHART, Arend. (1994), Electoral and Party Systems. Oxford, Oxford University Press.

LINZ, Juan e VALENZUELA, Arturo (eds.). (1994), The Failure of Presidential Democracy. Baltimore, The Johns Hopkins University Press.

NICOLAU, Jairo. (2004), “Partidos na República de 1946: Velhas Teses, Novos Dados”. Dados, vol. 47, nº 1, pp. 85-129.

RAE, Douglas. (1971) [1967], The Political Consequences of Electoral Laws. New Haven, Yale University Press.

e TAYLOR, Michael. (1970), The Analysis of Political Cleavages. New Haven, Yale University Press.

SANTOS, Wanderley Guilherme dos. (1961), Quem Dará o Golpe no Brasil. Rio de Janeiro, Civilização Brasileira.

. (1963), Reforma contra Reforma. Rio de Janeiro, Tempo Brasileiro.

. (1994), Regresso - Máscaras Institucionais do Liberalismo Oligárquico. Rio de Janeiro, Opera Nostra Editora.

. (1997a), "Da Oligarquia à Poliarquia - Competição Eleitoral e Processos Não-Encarceráveis". Série Estudos, nº 95, IUPERJ, outubro.

. (1997b), “Da Poliarquia à Oligarquia? - Eleições e Demanda por Renovação Parlamentar". Revista Sociedade e Estado, vol. XII, nํㅜ 1, UnB, 1ํㅗ.

. (1998), Décadas de Espanto e Uma Apologia Democrática. Rio de Janeiro, Rocco.

(1999), Governabilidade e Democracia Natural. Rio de Janeiro. Manuscrito.

__ (org.). (2002), Votos e Partidos. Almanaque de Dados Eleitorais: Brasil e Outros Países. Rio de Janeiro, Fundação Getulio Vargas Editora.

. (2003), O Cálculo do Conflito - Estabilidade e Crise na Política Brasileira. Belo Horizonte/Rio de Janeiro, Editora UFMG/IUPERJ.

SARTORI, Giovanni. (1976), Parties and Party Systems - A Framework for Analysis. Cambridge, Cambridge University Press.

TAAGEPERA, Rein e SHUGART, Matthew. (1989), Seats \& Votes, The Effects and Determinants of Electoral Systems. New Haven, Yale University Press. 


\section{GLOSSÁRIO}

MTR - Movimento Trabalhista Renovador

PAN - Partido dos Aposentados da Nação

PCB - Partido Comunista Brasileiro

PDC - Partido Democrata Cristão

PL - Partido Liberal

POT - Partido Orientador Trabalhista

PPS - Partido Popular Sindicalista

PR - Partido Republicano

PRB - Partido Ruralista Brasileiro

PRD - Partido Republicano Democrático

PRP - Partido da Representação Popular

PRProg - Partido Republicano Progressista

PRT - Partido Reformador Trabalhista

PSB - Partido Socialista Brasileiro

PSD - Partido Social Democrático

PSP - Partido Social Progressista

PST - Partido Social Trabalhista

PTB - Partido Trabalhista Brasileiro

PTN - Partido Trabalhista Nacional

UDN - União Democrática Nacional 


\section{ABSTRACT \\ Old Theses, New Data: A Methodological Analysis}

The author revisits the themes proposed by Jairo Nicolau in a previous article (Dados, vol. 47, no 1, 2004) concerning coalition votes in Brazil. Using election tables from the Superior Electoral Court and tables amended by Nicolau, the author evaluates whether the data studied by Nicolau support the thesis that he significantly modified the original Electoral Court data and thereby invalidated current hypotheses on variations in party votes from 1946 to 1962 in relation to the degree of nationalization in the Brazilian party system and fractionation rates, both during the same period. The author concludes that Nicolau's theses are invalid, including the use he makes of the concept of "effective number of parties".

Key words: political parties; party system; elections

\section{RÉSUMÉ}

Vieilles Thèses, Nouvelles Données: Une Analyse Méthodologique

Dans cet article, l'auteur reprend les sujets proposés par Jairo Nicolau dans un article précédent (Dados, vol. 47, no 1, 2004) traitant des votes des coalitions. Par le moyen de résultats électoraux présentés par le Tribunal Électoral Supérieur et des mêmes corrigés par Nicolau, on cherche à savoir si les données analysées par Nicolau suffisent à soutenir la thèse de sur ce qui aurait modifié de façon significative les données originelles du Tribunal Électoral Supérieur et, par là même, invalidé des hypothèses courantes sur des variations concernant les votes des partis dans la période 1946-1962, quant au degré de nationalisation du système des partis et aux indicateurs de répartition proportionnelle, tous les deux pendant la même période. En conclusion, on considère comme non soutenables les thèses de Nicolau, y compris l'usage qu'il fait de la notion de "nombre réel de partis".

Mots-clé: partis politiques; système des partis; élections 